\title{
Vivência acadêmica e expectativas de universitários ingressantes e concluintes
}

\author{
Érica Aparecida Igue ${ }^{1,2}$ - Pontifícia Universidade Católica de Campinas, Brasil \\ Isabel Cristina Dib Bariani - Pontifícia Universidade Católica de Campinas, Brasil \\ Pedro Vitor Barnabé Milanesi - Pontifícia Universidade Católica de Campinas, Brasil
}

\begin{abstract}
Resumo
Este estudo visou descrever as vivências acadêmicas de universitários, verificando se estas variavam em função do ano freqüentado, das expectativas dos alunos do $1^{\circ}$ ano quanto às vivências que teriam no curso e das expectativas que os discentes do $5^{\circ}$ ano tiveram ao entrar na universidade. Foram informantes 203 estudantes dos $1^{\circ}$ e $5^{\circ}$ anos de um curso superior de Psicologia. O Questionário de Vivências Acadêmicas - versão reduzida (QVA-r) foi aplicado juntamente com uma questão sobre as expectativas no período de ingresso à universidade. O QVA-r é um instrumento escalar que abrange cinco dimensões, a saber, pessoal, interpessoal, carreira, estudo e institucional. Considerando-se os anos freqüentados, análises estatísticas indicaram diferença significativa na dimensão institucional. Quanto às expectativas iniciais, foi encontrada diferença significativa apenas para os alunos de $5^{\circ}$ ano, na dimensão interpessoal e no total das dimensões.

Palavras-chave: Estudante universitário; Adaptação acadêmica; Ensino superior.
\end{abstract}

\section{Academic experiences and expectations of freshman and senior college students}

\begin{abstract}
This study aimed at describing the undergraduates' academic experiences and verified if there are variations related to year attended, the expectations from the freshman students concerning the experiences they would have during the course and the expectations related to the experiences the senior students had when they got into university. The informants were 2031 st year and 5th year psychology students, who answered the Questionário de Vivências Acadêmicas - versão reduzida (QVA-r) plus a question about the expectations related to the academic experiences they had when they just got into university. The QVA-r is scalar tool that includes five dimensions: personal, interpersonal, career, study and institutional. Considering the year attended, statistical analysis indicated significant difference related to the institutional dimension. Concerning the initial expectations, significant difference was found only for the 5 th year students, in the interpersonal dimension and in the total of the dimensions. Keywords: Undergraduates; Academic adaptation; Higher education.
\end{abstract}

\section{Introdução}

No Brasil, embora o número de vagas no ensino superior não seja suficiente para toda a população jovem com idade para nele ingressar (entre 18 e 25 anos), há um crescimento da população universitária que tem abarcado progressivamente camadas sociais mais heterogêneas (Polydoro, 2000). Essa diversificação é também relatada em estudos internacionais como, por exemplo, no de Almeida, Soares e Ferreira (1999), e refere-se, em geral, ao perfil socioeconômico e cultural, faixa etária, história acadêmica anterior, habilidades básicas e expectativas iniciais diante da graduação. Segundo os autores portugueses Almeida e Soares (2003), o ensino universitário se mostra "massificado", isto é, uma vez que se abre a camadas sociais mais heterogêneas, as universidades tentam atender a todos da mesma forma, utilizando as

\footnotetext{
1 Agradecimentos ao PIBIC/CNPq que concedeu bolsa à primeira autora para realização desse trabalho.

2 Endereço para correspondência:

Faculdade de Psicologia: Av. João Boyd Dunlop s/n - Jardim Ipaussurama, 13.059-900, Campinas, SP. E-mail: crisdib@puccampinas.edu.br
}

mesmas instalações, os mesmos cursos e propostas curriculares.

Vários estudiosos, tanto internacionais (como Almeida \& Soares, 2003) quanto nacionais (como Mercuri \& Polydoro, 2003), revelam que uma das preocupações crescentes que as universidades têm demonstrado é com relação à grande incidência de insucesso acadêmico dos seus alunos, que se manifesta de diversos modos, tais como: baixas classificações, absentismo, disciplinas em atraso, mudanças de curso, abandonos.

Almeida e Soares (2003) ressaltam que o primeiro ano da universidade, em especial, tem sido caracterizado como um

periodo crítico, potencializador de crises el ou desafios desenvolvimentais e como o principal determinante dos padrões de desenvolvimento estabelecidos pelos jovens ao longo da sua freqüencia universitária (p. 19).

Polydoro (2000) assevera que, para diversos autores, a entrada na universidade é uma transição bastante significativa para o indivíduo, nomeadamente pelo fato de ser um momento freqüentemente sincronizado com as mudanças $\mathrm{e}$ adaptações peculiares da adolescência e vida a- 
dulta. De acordo com a autora, as pesquisas têm compreendido a integração ao ensino superior como um fenômeno multifacetado, tendo três grandes elementos que o influenciam: condições pessoais, características institucionais e grupos de interação. Segundo Almeida e Soares (2003), o processo de transição e adaptação à universidade mostra-se complexo e multidimensional, dependente de fatores de caráter pessoal e contextual. $\mathrm{Na}$ mesma direção, Granado (2004) sustenta que o construto integração universitária é definido por dois componentes: por um lado, a troca entre as expectativas, habilidades e demais características dos estudantes; por outro lado, os componentes da universidade, isto é, sua comunidade, sua estrutura e elementos orgazacionais.

A revisão de Polydoro, Primi, Serpa, Zaroni \& Pombal (2001) demonstra que a integração à universidade tem aparecido como a variável central na importante decisão entre permanecer ou abandonar o objetivo de graduação. E em revisão da literatura a respeito deste processo, Almeida \& Soares (2003) apontam que, em estudos estrangeros, estima-se que mais da metade dos alunos que ingressam no ensino superior demonstra dificuldades nesta transição e que há um aumento dos níveis de psicopatologia na população universitária.

Segundo Rodrigues (1997), ao ingressar na universidade ainda há falta de um conhecimento mais concreto, por parte do estudante, sobre a carreira escolhida, o curso em que ingressou e o significado de estar na universidade. Ainda, para Thiessen e cols. (1999 apud Gonçalves, 2000), considerando a dinâmica que o novo contexto de estudo e aprendizagem pode provocar, é possível fazer a afirmação de que o ingresso no ensino superior pode ser um fator de movimento das expectativas do estudante. Pachane (2003) sustenta que os alunos chegam ao ensino superior com expectativas iniciais por vezes equivocadas, o que pode gerar uma série de decepções com sua vivência acadêmica.

Parece que as expectativas de entrada dos estudantes representam um dos fatores determinantes no processo de integração ao ensino superior. O desencontro entre as expectativas iniciais e o que a instituição realmente oferece pode se constituir em uma fonte de sentimentos antagônicos. Pachane (2003), em sua pesquisa, aponta para a importância das expectativas iniciais dos universitários, mostrando que eles buscam a universidade para a preparação profissional, no que se refere à titulação, qualificação e realização, e também, para o crescimento e realização pessoal, de modo que os estudantes têm expectativas quanto à qualidade do processo de formação, no que tange às atividades curriculares e extracurriculares e aos relacionamentos interpessoais. De acordo com a autora, os relatos dos alunos indicam frustrações e insatisfações em vários aspectos relativos à formação acadêmico-profissional, ao curso e à organização da universidade, e os maiores índices de satisfação dizem respeito a aspectos denominados como "desenvolvimento pessoal".

Discorrendo sobre o assunto, Polydoro (2000) assinala que, para o estudante, o período de ingresso é marcado pela euforia e idealização de que o novo ambiente educacional, que foi tão desejado, satisfaça suas necessidades, promova mudanças pessoais e o transforme em um profissional capacitado. Polydoro sustenta que podem ocorrer sentimentos de decepção e a impressão do aluno sobre a instituição pode deixar de ser tão positiva em decorrência do confronto da alta expectativa do estudante com as aulas, os professores e os procedimentos administrativos. A percepção da realidade da nova situação do contexto universitário em que ingressou e das necessidades de adaptação a ela, em confronto com a alta expectativa prévia, rompe com a "fantasia de que todas as dificuldades haviam se encerrado com o ingresso na universidade" (p. 21).

Similarmente ao que apontam as autoras brasileiras, Azevedo e Faria (2004) estudando o impacto da transição em universitários portugueses, sustentam que o novo contexto não só é exigente, como nem sempre é receptivo às expectativas dos alunos, o que pode gerar dificuldades aos estudantes.

Certamente, a satisfação do universitário em suas experiências acadêmicas poderá ser dificultada mediante a falta de recursos pessoais, inapropriado repertório acadêmico básico, inexistência de um projeto profissional definido e ausência de apoio da instituição. Sabe-se, então, que o sucesso no enfrentamento das demandas universitárias dependerá de uma série de variáveis pessoais e situacionais (Almeida \& Ferreira, 1999).

Segundo Astin (1993), o universitário tem um papel central no seu processo de formação, uma vez que é ele quem deve explorar ativamente as oportunidades oferecidas pelo ambiente. No entanto, há autores, tal como Santos (2000), que salientam, de modo especial, a responsabilidade das instituições de ensino superior perante o percurso de formação dos seus alunos. Também Nico (2000) sustenta ser de fundamental importância 
que as instituições proporcionem aos seus estudantes as condições adequadas para que experimentem satisfatório conforto acadêmico, importante indicador da qualidade institucional e essencial para a qualidade da aprendizagem. Por outro lado, Barros (2002) sustenta que reconhecer a relevância e promover a qualidade da vivência acadêmica é um desafio que encerra uma responsabilidade repartida, que engloba tanto uma nova filosofia curricular dos cursos e a organização das universidades, como a participação dos estudantes e das suas organizações estudantis. Indo ao encontro da posição de Barros, Schleich (2006, p. 29), a partir de seus estudos, aponta que

"o processo de integraça ocorre na interação entre estudante e instituição e deve ser compreendido de maneira reciproca e dinâmica em que estudantes também são ativos na modificação do ambiente institucional'.

Tinto (1975) afirma que a integração ao ensino superior ocorre quando o aluno passa a fazer parte da comunidade na qual está inserido e compartilha os valores comportamentais dos colegas e professores, as atitudes normativas, e respeita as exigências formais e informais.

Nesse sentido, o ajustamento ao contexto universitário deve ser considerado como um processo multifacetado, construído no cotidiano das relações estabelecidas entre o aluno e a instituição. Sendo assim, se, por um lado, aspectos relativos ao acadêmico - a sua história de vida, suas expectativas, habilidades e demais características e a qualidade do esforço estudantil, representado pelo envolvimento com a sua própria aprendizagem e desenvolvimento - desempenham um importante papel para a integração, por outro, os componentes da instituição, isto é, sua comunidade, sua estrutura e elementos organizacionais, também são essenciais, podendo facilitar ou não esse processo (Polydoro \& cols., 2001; Granado, 2004). Então, fica evidente que o processo de ajustamento ao contexto universitário é um processo complexo e multidimensional, que envolve diversos fatores, tanto de natureza intrapessoais como de natureza contextual (Almeida \& Soares, 2003).

O modo como cada estudante experiencia esse período é único, porém vários autores (dentre eles, Almeida \& Soares, 2003; Granado, Santos, Almeida, Soares \& Guisande, 2005; e Schleich, 2006) sustentam que, para que o universitário se integre, necessitará enfrentar múltiplas e complexas tarefas e solucionar os desafios propostos pelas vivências acadêmicas em quatro domí- nios principais - pessoal, social/interpessoal, acadêmico/estudo, e vocacional/carreira.

Não são todos os universitários que necessitam do mesmo tipo de apoio para a otimização dos seus níveis de adaptação acadêmica, sucesso escolar e desenvolvimento psicossocial. Isso se deve ao fato de que as motivações, as habilidades cognitivas, o background acadêmico anterior, as expectativas ou os níveis de autonomia podem ser diferenciados entre os estudantes, sendo possível encontrar, algumas vezes, diferenciações considerando-se grupos de alunos segundo o curso, o ano de freqüência ou o sexo (Almeida \& Soares, 2003).

Sendo assim, o impacto da vivência acadêmica nos estudantes universitários em geral e, em particular, nos que ingressam pela primeira vez no ensino superior mostra-se como um importante foco de investigação. Considerando esses aspectos, e levando em conta que grande parte da literatura disponível referente ao tema é estrangeira, tornase importante que se investigue acerca dessa problemática. Nesse contexto, o presente trabalho objetivou descrever as vivências acadêmicas de estudantes universitários, verificando se havia variação nestas em função: 1) de os alunos estarem cursando o ano inicial ou o ano final de seu curso; 2) das expectativas dos discentes do ano inicial, quanto às vivências que teriam ao longo do curso; e 3) das expectativas que os discentes do ano final tinham ao ingressarem no primeiro ano de seu curso.

\section{Método}

\section{Participantes}

Foram incluídos 203 universitários na amostra desta pesquisa, sendo que 103 freqüentavam o ano inicial e 100, o final de um curso de graduação em psicologia, com duração de cinco anos, de uma universidade confessional do estado de São Paulo. A escolha dsses períodos foi pela importância de se compreender melhor as vivências do universitário ingressante e dos que estão concluindo o curso.

A maior parte $(82,5 \%)$ dos alunos do primeiro ano do curso de psicologia afirmou ser do sexo feminino. As idades variaram de 17 a 46 anos e a média de idade foi de 20,17 anos. Quanto ao turno em que freqüentavam as aulas, 53,4\% estavam matriculados no período integral e 46,6\% no período noturno. Quanto aos estudantes do último ano do curso de psicologia, a maior parte (85\%) também afirmou ser do sexo feminino. As idades variaram de 21 a 44 anos e a média de idade foi de 
23,78 anos. Com relação ao turno em que freqüentavam o curso, $54 \%$ estavam matriculados no período integral e $46 \%$ no período noturno.

\section{Instrumento}

Para a coleta de informações da presente pesquisa foi utilizada a versão reduzida do Questionário de Vivências Acadêmicas (QVA-r), construída em 2001, em Portugal, por Leandro S. Almeida, Joaquim Armando Ferreira e Ana Paula Soares. Estudos desenvolvidos em Portugal demonstraram que esse instrumento conta com qualidade psicométrica (Almeida, Soares \& Ferreira, 2002). No Brasil, a escala foi submetida às adaptações lingüísticas necessárias para utilização em estudantes brasileiros por Villar e Santos, a partir do trabalho de Villar (2003) e a estudos de validação realizados por Granado (2004) e Santos, Noronha, Amaro e Villar (2005).

A versão brasileira do QVA-r dispõe de 55 itens, distribuídos em cindo dimensões relativas a áreas de adaptação acadêmica - pessoal (14 itens), interpessoal (12 itens), carreira (12 itens), estudo (9 itens) e institucional (8 itens). A dimensão pessoal refere-se ao bem-estar físico e psicológico; aborda aspectos como o equilíbrio emocional, a estabilidade afetiva, o otimismo, a tomada de decisões e a autoconfiança. A dimensão interpessoal refere-se às relações com os colegas e a competências de relacionamento em situações de maior intimidade; inclui o estabelecimento de amizades, a procura de ajuda. A dimensão carreira refere-se a sentimentos relacionados com o curso freqüentado e perspectivas de carreira; inclui a satisfação com o curso e percepção de competências para o curso. A dimensão estudo refere-se a hábitos de estudo e à gestão de tempo; inclui as rotinas de estudo, o planejamento do tempo, a utilização de recursos de aprendizagem, a preparação para os testes. A dimensão institucional refere-se à apreciação da instituição de ensino freqüentada; inclui os sentimentos relacionados à instituição, o desejo de permanecer ou mudar de instituição, conhecimento e apreciação das infra-estruturas (Almeida, Soares \& Ferreira, 2002).

Cada item deve ser respondido a partir da escolha de uma entre cinco alternativas: 1 . Nada a ver comigo, totalmente em desacordo, nunca acontece; 2. Pouco a ver comigo, muito em desacordo, poucas vezes acontece; 3 . Algumas vezes de acordo comigo e outras não, algumas vezes acontece, outras, não; 4. Bastante a ver comigo, muito de acordo, acontece muitas vezes; 5 . Tudo a ver comigo, totalmente de acordo, acontece sempre.
Ademais, após o QVA-r foi incluída uma pergunta que distinguia o indivíduo conforme o objetivo desta pesquisa, ou seja, indagando sobre a vivência acadêmica e expectativas iniciais dos alunos dos anos inicial e final do curso. Esse item foi submetido a uma testagem preliminar para verificação da inteligibilidade da questão e a sua versão final configurou-se conforme apresentado a seguir:

Ao ingressar na Universidade, as minhas expectativas quanto às vivências pessoais e acadêmicas que teria ao longo do curso eram:

( ) Muito altas

( ) Altas

( ) Médias

( ) Baixas

( ) Muito baixas

\section{Procedimentos}

O projeto da presente pesquisa foi analisado e aprovado pelo Comitê de Ética em Pesquisa com Seres Humanos da universidade em que o estudo se realizou, já contando com o consentimento do diretor da unidade selecionada para o desenvolvimento da investigação. Mediante a anuência do diretor do curso e dos professores responsáveis pelas aulas programadas para os dias da aplicação do QVA-r, exemplares foram entregues aos discentes em suas salas de aula, tendo todos assinado um Termo de Consentimento Livre e Esclarecido para participação em pesquisa, segundo a orientação da Resolução no 196/96 do Ministério da Saúde, a respeito de pesquisas envolvendo seres humanos.

Especificamente, ocorreram duas sessões coletivas de coleta de dados com alunos do primeiro ano do curso de psicologia, em uma turma de período integral e em uma de período vespertino/noturno. Com os estudantes concluintes a aplicação dos questionários aconteceu em horário de supervisão de estágio, e como é pequeno o número de alunos que compõem cada grupo de estágio, foram necessárias 12 sessões coletivas de coleta de dados, seis em cada período. Responderam ao instrumento todos os estudantes presentes nas salas de aula no momento da aplicação, que consentiram em participar da pesquisa, o que demandou cerca de 30 minutos.

As informações coletadas foram tratadas e os dados submetidos à análise estatística descritiva e inferencial, visando-se à consecução dos objetivos. É importante esclarecer que o instrumento contém 20 itens cujas afirmações têm sentido ne- 
gativo, os quais foram invertidos na planilha, passando a significar cunho positivo, de modo a não provocar distorção nos resultados das análises estatísticas, além de facilitar a interpretação desses. Do mesmo modo, os enunciados relativos a estes itens também sofreram alteração, ou seja, foi excluída ou acrescida a palavra "não" nessas afirmações mencionadas, para que todos os itens se configurassem positivamente quanto ao sentido. Assim, as exclusões ou inclusões da palavra "não" nas frases foram indicadas, respectivamente, $\mathrm{da}$ seguinte forma: [nã

\section{Resultados e discussão}

Inicialmente, são apresentados os resultados da análise estatística descritiva, a partir das médias obtidas. Posteriormente, são descritos os resultados da análise inferencial, a partir da qual se buscou analisar as vivências acadêmicas em relação ao ano freqüentado e quanto às expectativas iniciais acerca da vida universitária.

Convém lembrar que as médias poderiam variar entre 1,0 (um) e 5,0 (cinco), estando o menor valor associado à menor integração e o maior valor à maior integração à vida acadêmica.

$\mathrm{Na}$ dimensão pessoal, foi observada a média 3,26 para os ingressantes e 3,33 para os concluintes, sendo as mais baixas dentre todas as dimensões. Os seguintes itens se destacam por apresentar média inferior a 3,0 para ambos os anos: "Nos últimos tempos [não] me tornei mais pessimista" (1,93 e 2,16 para o $1^{\circ}$ e $5^{\circ}$ anos, respectivamente); "[Não] Consigo concentrar-me numa tarefa durante muito tempo" (2,81 e 2,46); "[Não] Tenho me sentido ansioso(a)" (2,69 e 2,59); "[Não] Costumo ter variações de humor" (médias 2,70 e 2,78). Essas médias são indicativas de uma percepção mais negativa referente a aspectos do bem-estar pessoal que, segundo Schleich (2006), pode estar associada ao momento de transição dos estudantes ingressantes e às demandas da fase de finalização do curso dos concluintes. Por outro lado, é interessante observar que, apesar dessa percepção negativa referente à estabilidade emocional, os alunos são capazes de estudar em um ritmo compatível ao de seus colegas, como sugere o item "Nos estudos [não] estou conseguindo acompanhar o ritmo dos meus colegas de turma" (médias 4,11 e 4,39 para o $1^{\circ}$ e $5^{\circ}$ ano respectivamente).

$\mathrm{Na}$ dimensão interpessoal, tanto os universitários de $1^{\circ}$ como os de $5^{\circ}$ ano obtiveram maior média no item "[Não] consigo fazer amizade com meus colegas" (4,65 e 4,55, respectivamente) e menor no item "Tomo a iniciativa de convidar os meus amigos para sair" (3,46 e 3,41, respectivamente). Os resultados totais dessa dimensão foram 3,98 e 3,94 para os ingressantes e concluintes, respectivamente. Esses indicadores revelam uma percepção favorável quanto ao que se refere às habilidades interpessoais. Bariani (2005) defende que dados como esses são importantes de ser considerados, uma vez que as relações interpessoais permeiam todo o processo educativo e contribuem para o seu sucesso. Polydoro (2000) ainda aponta os grupos de interação como um dos grandes elementos que influenciam o fenômeno da integração ao ensino superior.

Quanto à dimensão carreira, esta foi a que obteve as maiores médias, a saber, 4,25 para os alunos de primeiro ano e 4,18 para os de último. Tanto os ingressantes como os concluintes obtiveram maior resultado no item "Escolhi bem o curso que freqüento" (4,53 e 4,46, respectivamente), demonstrando um grau de satisfação positivo em relação às escolhas de curso e de carreira entre os estudantes de psicologia, além de terem identificado competência pessoal para o enfrentamento das demandas do curso, conforme sugere Schleich (2006).

A dimensão estudo apresentou as médias 3,47 para os ingressantes e 3,65 para os concluintes, sugerindo que os estudantes estavam razoavelmente integrados quanto a esse aspecto. Especificamente, ambos os grupos indicaram uma percepção bastante positiva para o item "Tenho capacidade para estudar" (4,13 e 4,47 para os alunos de primeiro e de último ano, respectivamente). Por outro lado, tanto os ingressantes quanto os concluintes demonstraram menor média no item "Faço um planejamento diário das coisas que tenho para fazer" (2,89 e 3,34, respectivamente). De acordo com Carelli e Santos (1998), estudar de forma eficiente envolve um esforço integral na busca da aprendizagem, o que requer que o aluno não só possua habilidades para os estudos, mas também que distribua adequadamente o tempo de que dispõe.

$\mathrm{Na}$ dimensão institucional, os estudantes de primeiro e último anos tiveram, respectivamente, 3,64 e 3,39. Os dois grupos apresentaram médias inferiores a 3,0 em alguns itens, dentre os quais foi comum o item "Conheço bem os serviços oferecidos pela minha universidade/faculdade" (2,94 e 2,97 para os ingressantes e concluintes, respectivamente). Observa-se que, quanto à conscientização dos universitários em 
relação aos dados de realidade de sua instituição, ambos os grupos de estudantes apresentaram médias baixas. Ou seja, os alunos afirmam que pouco conhecem os serviços por ela oferecidos. Assim, mostra-se a necessidade de providências para a melhora dessa situação - como, por exemplo, um projeto que integre adequadamente o estudante no contexto universitário em que se inseriu, uma vez que um dos elementos que influenciam a integração ao ensino superior são as características institucionais (Polydoro, 2000).

Ainda na dimensão institucional, foi curioso confrontar os resultados dos itens: "Mesmo que pudesse não mudaria de universidade/faculdade" (2,75 e 3,21 para os alunos de primeiro e quinto anos, respectivamente) e "Gostaria de concluir o meu curso na instituição que agora freqüento" (4,10 e 4,56 para os ingressantes e concluintes na instituição em que estão, se tivessem oportunidade mudariam.

Considerando-se os anos em que os discentes estavam matriculados, respectivamente). Esses dados sugerem que, apesar de os estudantes desejarem continuar, as análises estatísticas feitas por meio do Teste $\mathrm{t}$ de Student indicaram diferença significativa apenas na dimensão institucional $(\mathrm{t}=2,655 ; \mathrm{p}=0,009)$, tendo sido a média dos estudantes ingressantes maior $(3,64)$ do que a dos concluintes $(3,39)$, conforme já mencionado previamente.

Embora se esteja considerando como significativos os resultados de $\mathrm{p} \leq 0,05$, considera-se relevante destacar o resultado marginalmente significativo da dimensão estudo $(t=-1,965 ; \mathrm{p}=, 051)$, em que a média dos alunos de último ano foi maior (3,65 contra 3,47 para os discentes de primeiro ano).

Assim, parece que, quanto a aspectos institucionais e relativos ao estudo, as vivências acadêmicas dos estudantes variaram em função de estarem cursando o ano inicial ou final de seu curso.

A diferença significativa notada na dimensão institucional pode estar relacionada às expectativas, anteriores ao ingresso na universidade, relativas, particularmente, à instituição de ensino freqüentada, sendo que, no momento em que responderam ao instrumento, os alunos de $1^{\circ}$ ano podiam não ter ainda confrontado essas expectativas com dados da realidade relativos à instituição que as desmistificassem. Como dito anteriormente, Rodrigues (1997) ressalta que, ao ingressar na universidade, o discente ainda é carente de um conhecimento mais concreto sobre o significado de estar nela. Além disso, esse ainda é um período de idealização de que o ambiente universitário satisfaça suas necessidades, trazendo-lhe capacitação profissional e mudanças pessoais positivas (Polydoro, 2000). Os alunos de $5^{\circ}$ ano, por outro lado, podem ter levado em conta as experiências, ao longo de cinco anos, relativas à instituição e, dessa forma, tiveram oportunidade de confrontar suas fantasias sobre as vivências acadêmicas com a realidade. Isso pode ter possibilitado que confirmassem algumas de suas expectativas e que também se frustrassem quanto a alguns aspectos da instituição. Esse fato é comum, uma vez que, como sustenta Pachane (2003), os estudantes chegam ao ensino superior, algumas vezes, com expectativas iniciais equivocadas as quais, mais tarde, serão confrontadas com a realidade, sendo possível que gerem decepções.

No que concerne à maior média dos universitários do último ano na dimensão estudo, talvez seja possível inferir que, por já terem vivenciado quatro anos do curso, os estudantes foram, ao longo de todo esse tempo, adaptando-se de forma a conseguir melhores hábitos de estudo, competência para a gestão de tempo e utilização de recursos de aprendizagem (que são alguns dos aspectos avaliados pela dimensão estudo) mais otimizados que os alunos do primeiro ano, que recém saíram do ensino médio - período em que esses hábitos provavelmente diferiam, em aspectos diversos, dos necessários para uma melhor adaptação no contexto universitário. Conforme citam alguns autores (por exemplo, Almeida \& Soares, 2003; Santos, 1990a e 1990b; Mercuri, 1992; e Primi, Santos \& Vendramini, 2002), o background acadêmico anterior é um dos fatores que podem ser diferenciados entre os estudantes, sendo possível encontrar essas distinções, algumas vezes, considerando-se o período de freqüência do curso. Pode-se supor ainda que o planejamento e a dedicação aos estudos se impõem por questões de ordem prática, a saber, o fato de o último ano desse curso ser caracterizado essencialmente por atividades de estágios e a proximidade da vida profissional.

No que se refere às expectativas iniciais que os alunos tiveram quanto às vivências pessoais e acadêmicas que teriam ao longo do curso, os resultados apontaram que os discentes dos anos inicial e final (respectivamente) tiveram: $23,3 \%$ e $32,0 \%$ expectativas "muito altas"; $49,5 \%$ e $47,0 \%$ expectativas "altas"; $24,3 \%$ e $20,0 \%$ expectativas "médias"; e 2,9\% e 1,0\% expectativas "baixas". Apenas quatro estudantes responderam que tive- 
ram expectativas "baixas" e nenhum que teve expectativas "muito baixas" quanto às vivências que teriam ao longo do curso. Pelo reduzido número de discentes que indicou expectativas "baixas", estes foram excluídos da amostra ao se analisar estatisticamente se as vivências acadêmicas variavam em razão das referidas expectativas dos discentes.

Ao se considerar as expectativas dos estudantes de $1^{\circ}$ ano ao ingressar no ensino superior, não foi encontrada nenhuma diferença significativa, por meio da aplicação da ANOVA, entre os grupos com diferentes graus de expectativas.

Quanto aos alunos de último ano, foram encontradas diferenças significativas na dimensão interpessoal $(\mathrm{F}=3,315 ; p=0,041)$ e no total das dimensões $(\mathrm{F}=3,335 ; p=0,040)$, ao se comparar grupos em função do nível de suas expectativas ao ingressar na universidade. Ademais, na dimensão carreira, observou-se um resultado marginalmente significativo $(\mathrm{F}=2,763 ; p=0,068)$.

$\mathrm{Na}$ dimensão interpessoal, a maior média foi a dos discentes que tiveram expectativas "muito altas". Apesar de haver diferença significativa, os grupos não se distinguiram ao se aplicar o teste Tukey (post hoc test). Seria possível que os alunos de $5^{\circ}$ ano cujas expectativas iniciais eram "muito altas" estivessem também mais dispostos a estabelecer relações de amizade e a criar vínculos afetivos com as pessoas de seu curso, o que pode ter sido traduzido em média maior, na dimensão interpessoal, para esses informantes. Ao ingressar na universidade, esses estudantes também podem ter tido expectativas "muito altas", inclusive, por acreditarem que seriam bem sucedidos nos relacionamentos interpessoais. Existem autores (dentre eles, Cabrera \& cols., 1992 e Tinto, 1975 apud Polydoro, 2000) que defendem que o compromisso institucional se refere à expectativa pessoal do estudante de freqüentar uma determinada instituição de ensino superior e o estabelecimento desse compromisso depende das características acadêmicas e sociais da universidade. Ainda, enfatizam que o compromisso institucional é mais intensamente afetado pela integração social ao longo da experiência universitária. Dessa forma, pode-se apreender a importância da dimensão interpessoal nas vivências acadêmicas.

Foi possível verificar também que, no que diz respeito à dimensão carreira, para os alunos de último ano, apesar de ter sido apresentada uma diferença marginalmente significativa, os grupos de expectativas "muito altas", "altas" e "médias" não se distinguiram quando se analisou o teste
Tukey (post hoc test). A maior média foi a dos estudantes com expectativas "muito altas", que poderia ser indicativa de satisfação desses alunos quanto à escolha do curso, e, ao responderem ao instrumento, devem ter considerado as vivências que lhes foram proporcionadas ao longo de todos os anos que freqüentaram o curso.

Além disso, no total das dimensões para os alunos de $5^{\circ}$ ano, a diferença significativa apresentada pode ser indicativa de que, de forma geral, os alunos com expectativas "muito altas" apresentaram avaliação melhor das vivências acadêmicas porque estavam mais dispostos e motivados para investir seus recursos (material, intelectual, de tempo etc.) para elas.

\section{Considerações finais}

Embora este estudo apresente limitações, sobretudo pela reduzida amostra de informantes, espera-se que possa contribuir para uma melhor compreensão sobre o processo de adaptação do estudante ao ensino superior.

No que se refere às expectativas, para os alunos de $1^{\circ}$ ano não houve diferenças significativas nas suas vivências acadêmicas em virtude de terem expectativas positivas ou negativas. Já para os estudantes de $5^{\circ}$ ano, diferenças significativas foram reveladas nas análises dos dados. $\mathrm{Na}$ dimensão interpessoal, a maior média foi a dos alunos desse ano que tiveram expectativas "muito altas", sendo que essas expectativas podem ter influenciado na disposição dessas pessoas para estabelecer relações de amizade e criar vínculos afetivos com as pessoas de seu curso, o que pode ter sido traduzido em média maior, nessa dimensão, para eles. Vale considerar que uma das razões para que esses alunos, ao ingressar na universidade, tivessem "expectativas muito altas" pode ter sido por acreditarem que seriam bem sucedidos nos relacionamentos interpessoais.

A avaliação favorável dos universitários de $5^{\circ}$ ano na dimensão carreira (em que houve diferença marginalmente significativa) principalmente dos que tinham expectativas "muito altas", indicou um grau positivo de satisfação com as vivências relativas a esse aspecto, que podem ser reflexo de toda a experiência que tiveram ao longo de cinco anos. Seria interessante a realização de outros estudos em que se investigasse mais a fundo o grau de satisfação dos alunos de último ano com relação à carreira por eles escolhida.

Alguns dados obtidos neste estudo apontaram que houve aspectos, relativos ao estado psi- 
cológico dos discentes, que tiveram avaliação baixa. Quanto à conscientização dos alunos em relação aos dados de realidade de sua instituição, observou-se que eles ainda não conhecem bem os serviços oferecidos pela sua universidade. Algumas reflexões a respeito dessas informações poderiam conduzir a medidas que talvez pudessem amenizar os problemas em questão. Seria possível a universidade acolher os estudantes de forma a oferecerlhes apoio, inclusive psicológico, para que tivessem uma melhor qualidade das vivências acadêmicas? $\mathrm{E}$, ao ingressar na universidade, talvez fosse importante um projeto de integração dos calouros que abordasse com eficácia os serviços fundamentais já oferecidos por ela. Outras alternativas de apoio também podem ser consideradas para que se promova maior qualidade nas vivências acadêmicas desde os anos iniciais do curso. Deve-se, por outro lado, também conscientizar o aluno de que ele também deve se interessar em conhecer melhor o que a instituição lhe proporciona, já que os desenvolvimentos dos estudantes não dependem unicamente do impacto da universidade sobre eles, mas, sim, do esforço e do tipo de envolvimento do aluno em relação aos recursos oferecidos pela instituição e às experiências externas. Segundo Astin (1993), o universitário tem um papel central, uma vez que é ele quem deve explorar ativamente as oportunidades oferecidas pelo ambiente.

Os resultados sugerem que cursar o primeiro ou último ano do curso influiu nas vivências acadêmicas dos estudantes, de modo que, ao que parece, o acúmulo de experiências percorridas pelos estudantes de $5^{\circ}$ ano e o conseqüente amadurecimento proporcionaram-lhes melhores hábitos de estudo. Isso confirma o que alguns autores defendem: que o background acadêmico anterior pode ser diferente entre os discentes, e essa diferenciação pode ser encontrada entre estudantes matriculados em anos distintos (Almeida \& cols., 2000; Soares, Ferreira \& Almeida, 2002, apud Almeida \& Soares, 2003). Além disso, a média menor dos discentes de último ano na dimensão institucional pode não ser tão negativa, uma vez que, no item "Gostaria de concluir o meu curso na instituição que agora freqüento", obteve-se uma avaliação alta $(4,56)$, o que talvez possa denotar que a instituição em que estavam matriculados era vista como bem qualificada para sua formação e que ela detinha prestígio no mercado.

Foi possível entender que as expectativas iniciais dos alunos ao ingressarem na universidade acarretaram diferenças significativas para os estudantes de $5^{\circ}$ ano. De forma geral, os resultados apontaram que os discentes com expectativas mais altas apresentaram avaliação melhor das vivências acadêmicas por estarem mais dispostos e motivados para investirem seus recursos nelas. Dessa forma, considerando a afirmação de Thiessen e cols. (1999 apud Gonçalves, 2000) de que o ingresso na universidade pode ser fator de movimento de expectativas dos estudantes, verificamos que essas expectativas iniciais são fatores importantes que podem influenciar na vivência acadêmica.

Espera-se que os resultados aqui apresentados, apesar de suas limitações, corroborem o planejamento de medidas educacionais que visem à integração de estudantes ao ensino superior e que também, que sirvam de inspiração para que outros estudiosos se dediquem a este relevante assunto.

\section{Referências}

Almeida, L. S. \& Ferreira, J. A. G. (1999). Adaptação e rendimento acadêmico no ensino superior: Fundamentação e validação de uma escala de avaliação de vivências acadêmicas. Psicologia: Teoria, Investigação e Prática. Braga, Portugal, 1, 157-170.

Almeida, L. S. \& Soares, A. P. (2003). Os estudantes universitários: sucesso escolar e desenvolvimento psicossocial. Em E. Mercuri \& S. A. J. Polydoro (Orgs.). Estudante universitário: caracteristicas e experiências de formação. Taubaté: Cabral.

Almeida, L. S., Soares, A. P. C. \& Ferreira, J. A. (1999). Adaptação, rendimento e desenvolvimento dos estudantes no ensino superior: construção/ validação do questionário de vivências acadêmicas. Relatório de investigação. Braga, Portugal: Universidade do Minho - Centro de Estudos em Educação e Psicologia.

Almeida, L. S., Soares, A. P. C. \& Ferreira, J. A. (2002). Questionário de Vivências Acadêmicas (QVA-r): Avaliação do ajustamento dos estudantes universitários. Avaliação Psicológica, 2, 81-93.

Astin, A. W. (1993). What matters in college? Four critical years revisited. San Francisco: Jossey-Bass.

Azevedo, A. S. \& Faria, L. (2004) Experiências de transição acadêmica: Qualidades psicométricas de um questionário para o contexto universitário. Trabalho apresentado na X Conferencia Internacional - Avaliação Psicológica: Formas e Contextos. Braga, Portugal: Psiquilíbrios. 
Bariani, I. C. D. (2005). Vivência acadêmica de universitários ingressantes. Relatório técnico de pesquisa. Campinas: Faculdade de Psicologia, PUC.

Barros, M. (2002). A relevância e a qualidade da vivência acadêmica: Um percurso de formação activa: 99-106. Em A. S. Pouzada, L. S. Almeida \& R. M. Vasconcelos (Orgs). Contextos e dinâmicas da vida acadêmica. Portugal: Guimarães.

Carelli, M. J. G. \& Santos, A. A. A. dos (1998). Condições temporais e pessoais de estudo em universitários. Psicologia Escolar e Educacional, 2 (1), 265-278.

Gonçalves, F. R. (2000). Movimentação das expectativas dos alunos durante o decurso do seu primeiro ano na Universidade. Em A. P. Soares, A. Osório, J. V. Capela, L. S. Almeida, R. M. Vasconcelos \& S. M. Caíres (Eds.). Transição para o ensino superior. Braga: Universidade do Minho.

Granado, J. I. F. (2004). Vivência acadêmica de universitários brasileiros: estudo de validade e precisão do QVA-R. Dissertação de Mestrado. Itatiba: Universidade São Francisco.

Granado, J. I. F., Santos, A. A. A. dos, Almeida, L. S., Soares, A. P. \& Guisande, M. A. (2005). Integração acadêmica de estudantes universitários: Contributos para a adaptação e validação do QVA-r no Brasil. Psicologia e Educação (1), 33- 43 .

Mercuri, E. N. G. da S. (1992). Condições espaciais, materiais, temporais e pessoais para o estudo, segundo depoimentos de alunos e professores de cursos de graduação da UNICAMP. Tese de Doutorado. Cmapinas: UNICAMP-FE.

Mercuri, E. \& Polydoro, S. A. J. (2003). O compromisso com o curso no processo de permanência/ evasão no ensino superior: algumas contribuições. Em E. Mercuri \& S. A. J. Polydoro (Orgs.). Estudante universitário: características e experiências de formação. Taubaté: Cabral.

Nico, J. B. (2000). O conforto acadêmico do(a) caloiro(a) (pp. 161-166). Em A. P. Soares, A. Osório, J. V. Capela, L. S. Almeida, R. M. Vasconcelos \& S. M. Caíres (Orgs.). Transição para o ensino superior. Braga, Portugal: Reitoria da Universidade do Minho.

Pachane, G. G. (2003). A experiência universitária e sua contribuição ao desenvolvimento pessoal do aluno. Em E. Mercuri \& S. A. J. Polydoro
(Orgs.). Estudante universitário: características e experiências de formação. Taubaté: Cabral.

Polydoro, S. A. J. (2000). O trancamento de matrícula na trajetória acadêmica do universitário: condições de saída e de retorno à instituição. Tese de Doutorado. Campinas: UNICAMP-Faculdade de Educação.

Polydoro, S. A. J., Primi, R., Serpa, M. de N. da F., Zaroni, M. M. H. \& Pombal, K. C. P. (2001). Desenvolvimento de uma escala de integração ao ensino superior. Psico-USF, 6(1), 11-17.

Primi, R., Santos, A. A. A. dos \& Vendramini, C. M. (2002). Habilidades Básicas e Desempenho Acadêmico em Universitários Ingressantes. Estudos de Psicologia, Campinas, SP, 7 (1), 47-55.

Rodrigues, L. C. (1997). Rituais na universidade: uma etnografia na UNICAMP. Campinas, SP: Área de Publicações CMU/Unicamp.

Santos, A. A. A. dos (1990a). Compreensão em leitura na universidade: um estudo comparativo entre dois procedimentos de treino. Estudos de Psicologia, Campinas, SP, 7 (2), 39-53.

Santos, A. A. A. dos (1990b). Leitura entre universitários: diagnóstico e remediação. Tese de Doutorado. São Paulo: Instituto de Psicologia, USP.

Santos, A. A. A. dos, Noronha, A. P. P., Amaro, C. B. \& e Villar, J. (2005). Questionário de Vivência Acadêmica: Estudo da consistência interna do instrumento no contexto brasileiro. Em M. C. R. A. Joly, A. A. A. Santos \& F. F. Sisto (Orgs.). Questões do cotidiano universitário. São Paulo: Casa do Psicólogo.

Santos, S. M. dos (2000). As responsabilidades da Universidade no acesso ao ensino superior (pp. 69-78). Em A. P. Soares, A. Osório, J. V. Capela, L. S. Almeida, R. M. Vasconcelos \& S. M. Caíres (Orgs.). Transição para o ensino superior. Braga, Portugal: Reitoria da Universidade do Minho.

Schleich, A. L. R. (2006). Integração na educação superior e satisfação acadêmica de estudantes ingressantes $e$ concluintes. Dissertação de Mestrado. Campinas: Universidade Estadual de Campinas.

Tinto, V. (1975). Dropout from higher education: A theoretical synthesis of recent research. Review of Educational Research, 45(1), 89-125.

Villar, J. D. (2003). Adaptação de Questionário de Vivência Universitária com estudantes de arquitetura $e$ 
Sobre os autores:

Érica Aparecida Igue é graduada em Psicologia pela Pontifícia Universidade Católica de Campinas desde o ano de 2005; bolsista de iniciação científica PIBIC/CNPq no período de agosto de 2004 a julho de 2005. Atualmente, exerce atividades profissionais em Psicologia Clínica.

Isabel Cristina Dib Bariani é graduada em Psicologia pela Pontifícia Universidade Católica de Campinas, mestre e doutora em Educação na área de concentração Psicologia Educacional pela Universidade Estadual de Campinas e docente da Faculdade de Psicologia da Pontifícia Universidade Católica de Campinas.

Pedro Vitor Barnabé Milanesi é graduado em Psicologia pela Pontifícia Universidade Católica de Campinas desde 2006, atualmente mestrando e bolsista CNPq do Programa de Pós-Graduação em Psicologia Ciência e Profissão da Pontifícia Universidade Católica de Campinas. 